Journal Name

COMMUNICATION

Received 00th January 20xx, Accepted 00th January 20xx

DOI: $10.1039 / \times 0 \times x 00000 x$

\section{Modulation of catalyst enantioselectivity through reversible assembly of supramolecular helices.}

\author{
Yan Li, ${ }^{a}$ Xavier Caumes, ${ }^{a}$ Matthieu Raynal*a and Laurent Bouteiller ${ }^{\text {a }}$
}

www.rsc.org/

A multi-configurable catalyst, for which the degree of enantioinduction in successive reactions is varied between $6 \%$ e.e. and $52 \%$ e.e., is achieved by supporting copper centres at the periphery of supramolecular helices. Precise characterization of the co-assemblies corroborates the relation between helices length and catalyst selectivity.

External triggers such as light, redox potential, chemical species or mechanical energy emerged as a new strategy to control chemical processes. ${ }^{1}$ Temporal control of chemical reactions has been achieved by toggling a catalyst back and forth between its active and inactive states. This switchable capacity of the catalyst is exploited in the realm of sequential reactions, e.g. allowing to finely control polymerization processes $^{2}$ or tandem reactions. ${ }^{3}$ Much less effort has been devoted to the design of stimuli-responsive asymmetric catalysts. ${ }^{4}$ Predictable control of the stereochemical direction for a single catalyst is achieved by supporting intrinsically achiral centres on a chirally-switchable platform such as overcrowded alkenes, ${ }^{5}$ stereodynamic ligands, ${ }^{6}$ redoxconfigurable copper complexes, ${ }^{7}$ foldamers ${ }^{8}$ or polymers. ${ }^{9}$ Alternatively, chemical additives, ${ }^{10}$ light ${ }^{11}$ and redox potential ${ }^{12}$ were employed to improve the degree of enantioinduction, ${ }^{13}$ including a recent example of a rationallydesigned asymmetric auto-inductive process. ${ }^{14}$ However, implementation of these elaborated catalytic systems in consecutive reactions or polymerization reactions will require a better control of their dynamic properties. Molecular catalysts for the preparation of atactic isotactic multi stereoblock copolymers are sparse ${ }^{15}$ and, in that regard, establishing the design elements for a dynamic and multiconfigurable catalytic system will constitute an important advance.

In parallel, the reversible and dynamic properties of supramolecular chiral assemblies ${ }^{16}$ have been exploited in asymmetric catalysis. ${ }^{17}$ We previously demonstrated that a significant degree of enantiocontrol can be achieved by supporting metal catalytic centres at the periphery of the helical assemblies formed by benzene-1,3,5-tricarboxamide

\footnotetext{
a. Sorbonne Université CNRS, Institut Parisien de Chimie Moléculaire, Equipe Chimie des Polymères, 4 Place Jussieu, 75005 Paris (France) e-mail:

matthieu.raynal@upmc.fr.

$\dagger$ Electronic Supplementary Information (ESI) available: general procedures, Chart S1, supplementary figures (Figs. S1-S8), tables S1-S3, and procedures for catalytic experiments. See DOI: 10.1039/x0xx00000x
}

monomers (BTA).9i,18 Co-assembly between an achiral BTA ligand and an enantiopure BTA co-monomer into homochiral helices allows real-time control of the enantioselectivity. The stereochemical direction and the degree of asymmetric induction of the catalytic reaction are related to the handedness and the optical purity, respectively, of the helical BTA assemblies. For further development of this new class of catalysts, it is of utmost importance to probe how the enantioselectivity is affected by the average length of the helices. Herein, we show that reversible assembly of BTA monomers into helices of different length constitutes a simple method to vary the degree of enantioinduction of a catalytic reaction (Chart 1 ).

The preparation of BTA helices of controlled sizes is hampered by the dynamic character of the assemblies. Moreover, hydrogen-bonded supramolecular polymers form onedimensional assemblies whose stability are particularly sensitive to the environment. ${ }^{19}$ Anions have notably been used to reduce the chain length of urea-based supramolecular polymers without affecting their structure. ${ }^{20}$ Therefore, we envisioned that the length of BTA assemblies could be modulated in a reversible manner by first adding an anion and then removing it, e.g. through a salt metathesis reaction leading to its co-precipitation with a cation (Chart 1). ${ }^{21}$

To implement our concept, we chose as a reference the catalytic mixture composed of an achiral BTA ligand BTA ${ }^{\text {PPh2 }}$ ( 6 mol\%) an enantiopure co-monomer BTA (R)-Cha (6.6 mol\%), $\left[\mathrm{Cu}(\mathrm{OAc})_{2} \cdot \mathrm{H}_{2} \mathrm{O}\right](3 \mathrm{~mol} \%)$ and $\mathrm{PhSiH}_{3}$ since it furnished the hydrosilylation product of 1-(4-nitrophenyl)ethanone (NPnone) with significant enantioselectivity $(54 \pm 1 \%$ e.e. at $293 \mathrm{~K}$ in toluene). ${ }^{9 i}$ A combination of spectroscopic analyses and catalytic experiments indicated that the chirality of the comonomer controls the handedness of the helices and thus the stereochemical direction of the hydrosilylation reaction. Two preliminary experiments now confirm that the size of the BTA assemblies also affects the level of asymmetric induction (Table S1, ESI + ): (i) in THF, BTAs are molecularly dissolved and no selectivity is observed, and (ii) when the reaction is conducted with a concentration in BTA ${ }^{\text {PPh2 }}$ close to its critical concentration in toluene, the selectivity is significantly decreased ( $19 \%$ e.e.). In the latter case, it is likely that at this concentration the assemblies are too short to arrange all the copper centers in a suitable chiral environment.

We next investigated the influence of TPPCI (tetraphenylphosphonium chloride) on the performance of 

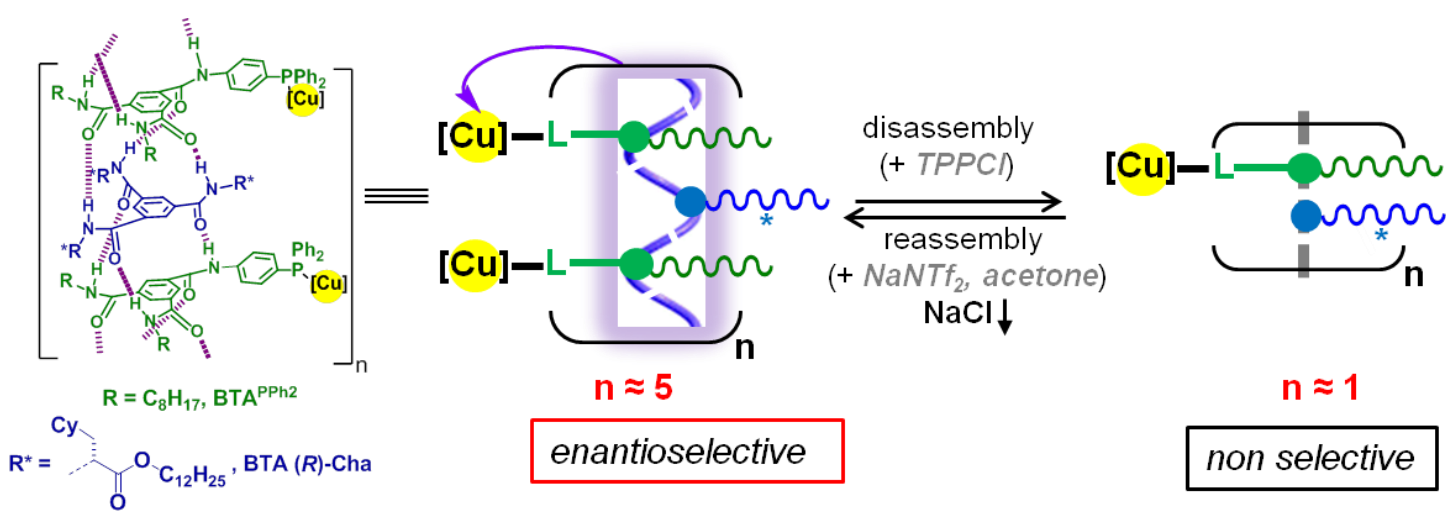

$\mathrm{n} \approx 1$

non selective

Chart 1 Schematic representation of the present concept. Supramolecular helices, formed by co-assembly between an achiral BTA ligand (BTA PPh2) coordinated to Cu

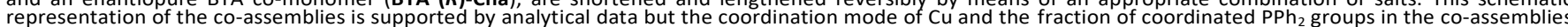
are not known.

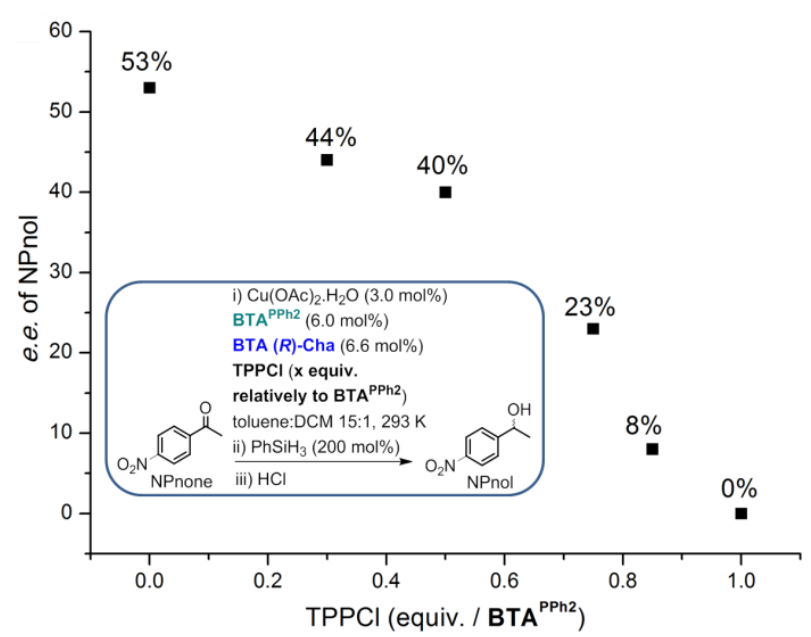

Fig. 1 Enantioselectivity as a function of the amount of TPPCl. See the precise conditions in Table S.1. Conversions (after $1 \mathrm{~h}$ ): $>99 \%$ ( 0 and 0.3 equiv. of TPPCl), $97 \%$ ( 0.5 equiv.), $91 \%$ ( 0.75 equiv.), $75 \%$ ( 0.85 equiv.) and $63 \%$ ( 1.0 equiv.).

the catalytic system of reference (Fig. 1). ${ }^{21}$ The first (unanticipated) effect is the slowdown of the reaction rate: the higher the amount of TPPCl, the lower the rate (Table S1). Whilst the origin of this negative effect of chloride anions on the reaction rate has not been established for the present case, inhibition of metal-catalysed reactions by soluble halogen anions has some precedent in the literature. ${ }^{22}$ The decreased rate for the non-selective state of the supramolecular catalyst is not detrimental since good conversions can be achieved by increasing the amount of silane and the reaction time (vide infra). The second (anticipated) effect is a gradual decrease of the enantioselectivity as a function of the amount of chloride anions in the catalytic mixture: from $44 \%$ e.e. ( 0.3 equiv. relative to $\mathrm{BTA}^{\mathrm{PPh} 2}$ ) to $0 \%$ e.e. (1.0 equiv.). $¥$ The fact that a high content of TPPCl relatively to $\mathbf{B T A}^{\mathrm{PPh} 2}$ is required to completely erase the selectivity suggests that the length of the assemblies should be shortened down to very short aggregates to be nonselective (vide infra). It is interesting to note that TPPCI does not act as dual on-off selectivity switch but rather allows programmable modulation of the degree of enantioinduction (signal output) in between fully racemic, and optimal enantiomeric preference ( $53 \%$ e.e.) by simply changing the concentration of TPPCl (signal input).

The nature of the co-assemblies formed between BTA PPh2 $^{\text {Pnd }}$ BTA $(\boldsymbol{R})$-Cha in toluene and their reversible assembly have been precisely characterized by means of Fourier-Transform Infrared (FT-IR), Nuclear Magnetic Resonance (NMR), Small Angle Neutron Scattering (SANS) and Circular Dichroism (CD) analyses. The "pristine" co-assemblies, i.e. in absence of any additives, are very long $\left(D P_{n} \approx 250\right)$, stack with a single molecule in the cross-section and contain approximately two BTA $^{\text {PPh2 }}$ molecules for one BTA ( $R$ )-Cha (Figs. S1-S2). They form homochiral left-handed helices as deduced from $C D$ analysis (Fig. 2b). ${ }^{9 i}$ The coordination of BTA ${ }^{\text {PPh2 }}$ to copper does not significantly change the structure of the helical co-assemblies (Fig. S4). However, both SANS (Fig. S5) and FT-IR (Figs. 2a) analyses confirm that the length of the co-assemblies is drastically decreased in presence of 1.0 equiv. of TPPCI. Notably, in FT-IR, the bonded amide band is reduced whereas the free amide band is increased in presence of TPPCl (green arrows in Fig. 2a). Deconvolution of the ester $\mathrm{C}=\mathrm{O}$ and amide $\mathrm{C}=\mathrm{O}$ bands yields an estimation of $\mathrm{DP}_{\mathrm{n}} \approx 2$ for the average length of the co-assemblies in presence of 1.0 equiv. of TPPCI (Fig. S7). The absence of an Induced CD (ICD) signal ${ }^{23}$ for this mixture (Fig. 2b) corroborates the fact that these objects are likely too small to adopt a helical configuration and explains the absence of selectivity for the catalytic reaction (vide supra).

$\mathrm{NaNTf}_{2}$ ( $\mathrm{Tf}=$ triflimide) was selected to trigger the metathesis reaction because of the weak coordination ability and the known chemical stability of the $\mathrm{NTf}_{2}$ anion. ${ }^{24} \mathrm{NaNTf}_{2}$ is introduced in solution in acetone as we observe a good solubility of this salt in the three-solvent mixture (toluene:DCM:acetone 15:1:1). In these conditions, reassembly 


\section{Journal Name}

- "pristine" $D P_{n} \approx 250$, "run 1" $=+T P P C \mid, D_{n} \approx 2$, "run 2"

- + TPPCl + NaNTf, $6<\mathrm{DP}_{\mathrm{n}}<15$, "run 3"

$=+\mathrm{DCM}+$ acetone, $6<\mathrm{DP}_{\mathrm{n}}<22$, "run 3 without salts"

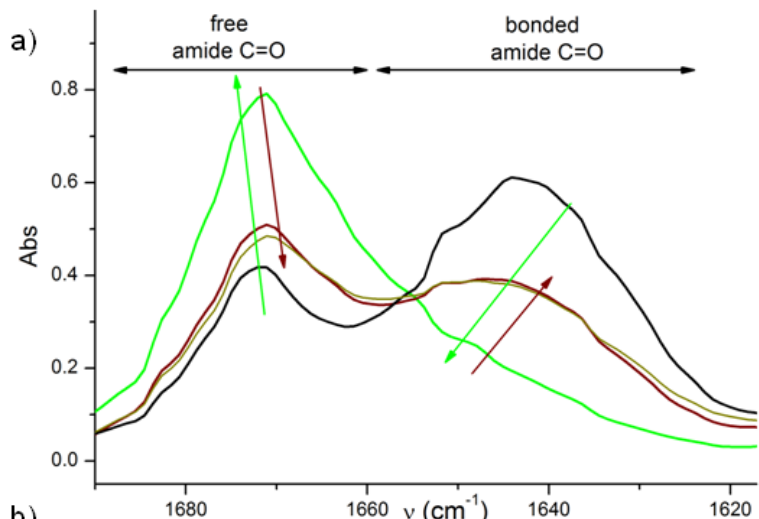

b)

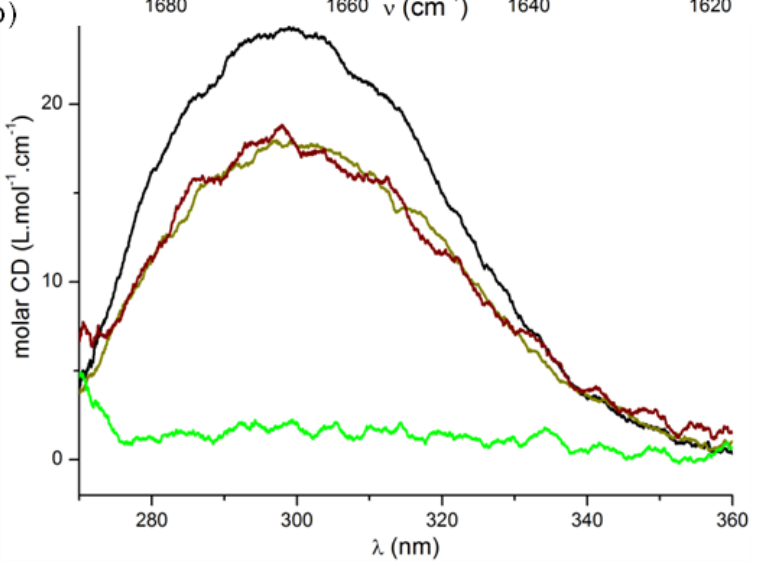

Fig. 2 Characterization of the reversible assembly of supramolecular helices. FT-IR (a) and CD (b) analyses of the co-assemblies in absence and presence of salts (293 K). The concentrations in ligand and co-monomer are close to those of catalytic experiments indicated in red. The $D P_{n}$ values have been estimated by means of SANS and FT-IR analyses (Figs. S1 and S7). In the FT-IR spectra, both dimers of BTA (R)-Cha ${ }^{25}$ and stack ends contribute to the free amide $\mathrm{C}=\mathrm{O}$ band. The observed $\mathrm{CD}$ signal belongs to $\mathrm{BTA}^{\mathrm{PPh2}}$ only and is thus an ICD signal ${ }^{23}$ which reflects the chiral environment of the ligand..$^{9 i}$ For the "pristine" co-assemblies, this signal is of comparable intensity $\left(\Delta \varepsilon=24 \mathrm{~L}_{\mathrm{mol}}{ }^{-1} \cdot \mathrm{cm}^{-1}\right)$ to that previously observed in methylcyclohexane $\left(\Delta \varepsilon=17 \mathrm{~L} . \mathrm{mol}^{-1} \cdot \mathrm{cm}^{-1}\right)$ inferring the presence of homochiral left-handed helices..$^{9 i}$

is evidenced by the increased intensity of the bonded amide band and the decreased intensity of the free amide band (wine arrows in Fig. 2a). Also, this sample exhibits a significant ICD signal (Fig. 2b) which infers that the ligand has recovered a chiral environment.

The above experiments have established the use of TPPCI (1.0 equiv., added as a solution in DCM) and $\mathrm{NaNTf}_{2}$ (1.0 equiv., added as a solution in acetone) as a suitable combination of salts for the reversible assembly of the supramolecular helices.§ We thus investigated whether this strategy can be used to switch the enantioselectivity of our catalytic system of reference. Sequential additions of NPnone, silane and salts (Fig. 3 top) have been performed in the following order: no salt (run 1), TPPCl (run 2), NaNTf 2 (run 3), TPPCl (run 4) and $\mathrm{NaNTf}_{2}$ (run 5). An excess of silane has been engaged and the reaction times have been adapted so that a conversion superior or equal to $84 \%$ was achieved for each run (except for run 4 , conversion=53\%). The enantiomeric excess for each run was calculated from the cumulated e.e. obtained by chiral GC analyses of the aliquots as detailed in Table S3. As shown in
COMMUNICATION
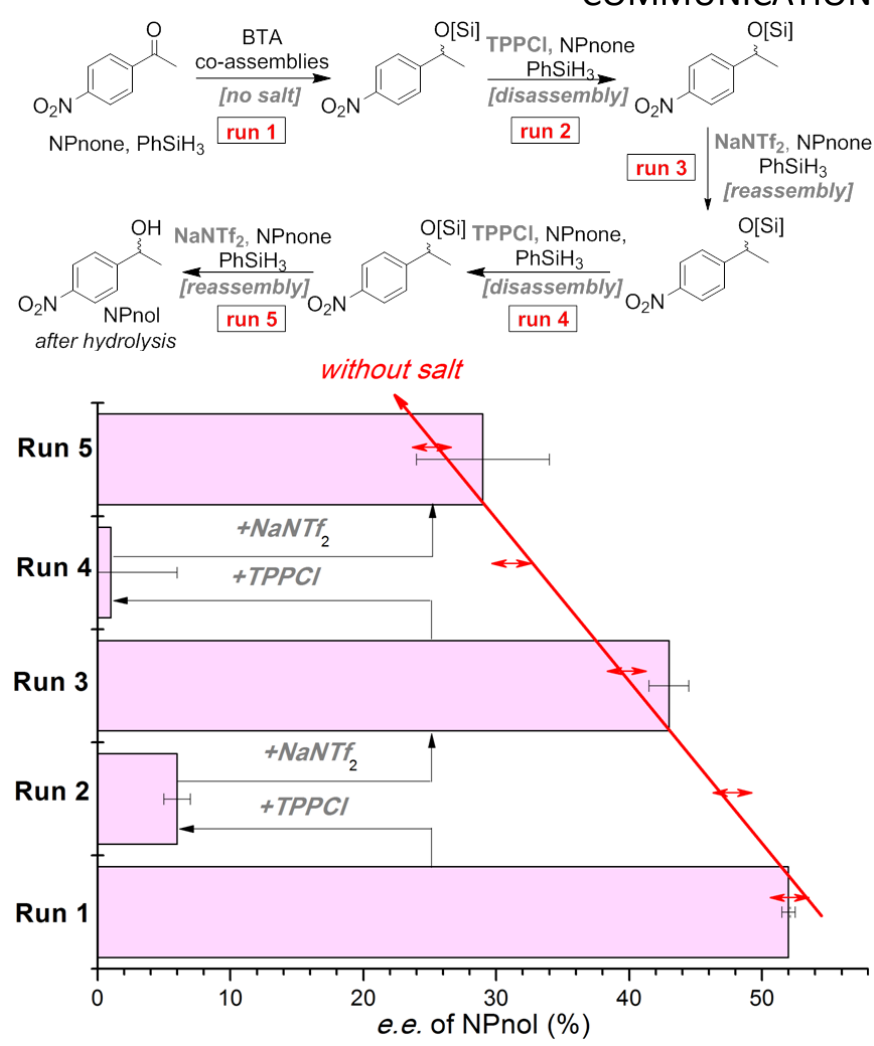

Fig.3 Modulation of the enantioselectivity of the supramolecular catalyst involved in the hydrosilylation of several equivalents of NPnone added sequentially in the reaction mixture. Top: description of the run. TPPCl and $\mathrm{NaNTf}_{2}$ are added as solutions in DCM and acetone, respectively so that the solvent nature is: toluene (run 1), toluene:DCM 15:1 (run 2), toluene:DCM:acetone 15:1:1 (run 3), toluene:DCM:acetone 15:2:1 (run 4) and toluene:DCM:acetone 15:2:2 (run 5). Bottom: enantioselectivity obtained for each run. Conversions: $99 \%$ (run 1), $86 \%$ (run 2), $89 \%$ (run 3), 53\% (run 4) and $84 \%$ (run 5). Double arrows represent the selectivity obtained in the same solvent but in absence of salts. For the determination of the e.es. and the conversions, see Table S3.

Fig. 3, the state of the supramolecular copper catalyst is alternatively selective $(29-52 \%$ e.e.) and poorly selective $(0-6 \%$ e.e.). More precisely, a significant decrease of the enantioselectivity is found for the run $2(6 \pm 1 \%$ e.e.) and run 4 $(0 \pm 5 \%$ e.e. $)$, as a result of the disassembly of the supramolecular helices supporting the catalytic centres in presence of TPPCI. The selectivities of run $3(43 \pm 1.5 \%$ e.e.) and run $5(29 \pm 5 \%$ e.e.) are significantly higher than those of run 2 and run 4, which corroborates the reversible assembly of the BTA helices and validates our concept.

We were intrigued by the decreased selectivity for run 3 and 5 compared to run 1 and therefore investigated its origin. After reassembly (in presence of TPPCl and $\mathrm{NaNTf}_{2}$, run 3), the coassemblies have $\mathrm{DP}_{\mathrm{n}}$ in between 6 and 15 much lower than that of "pristine" co-assemblies (run $1, \mathrm{DP}_{\mathrm{n}} \approx 250$ ) as evidenced by FT-IR analyses (Fig. 2a). In fact, this shortening of the helices is mostly due to the presence of co-added solvents (DCM and acetone) as demonstrated by: (i) control catalytic experiments in absence of TPPCl and $\mathrm{NaNTf}_{2}$ (double red arrows, Fig. 3) which provide roughly the same selectivity for run 3 and 5, (ii) the fact that, in toluene:DCM:acetone 15:1:1, the FT-IR, NMR and CD spectra of the co-assemblies in absence or presence of TPPCl and $\mathrm{NaNTf}_{2}$ are similar (Figs. 2 and S7). This substantiates the efficiency of the metathesis salt reaction and infers that full reassembly is hampered by the competitive 


\section{COMMUNICATION}

and polar nature of the solvents employed to dissolve the salts. Interestingly, the selectivity decrease (19\%) observed after a single disassembly/reassembly switch (from $52 \%$ e.e. for run 1 to $43 \%$ e.e. for run 3) correlates well with the lower intensity (25\%) of the ICD signal measured for co-assemblies in presence of the salt mixture and the co-solvents (Fig. 2b). There is thus a good correlation between the average length of the assemblies, the chiral environment of the ligand and the selectivity of the reaction (Table S2). For the present catalytic system, the critical length of the supramolecular helices required to locate most of the copper centres in a chiral environment suitable for asymmetric induction is thus in the range of a ten monomers.

In conclusion, a multi-configurable catalyst is obtained by reversibly shortening and lengthening the supramolecular helices formed by assembly of BTA monomers. This can undoubtedly be extended to other families of hydrogenbonded supramolecular polymers and organogels with the aim of tuning their macroscopic properties. Further progress in the design of such functional supramolecular assemblies is required for the implementation of more efficient smart systems in the field of switchable catalysis.

This work was supported by the French Agence Nationale de la Recherche (project ANR-13-BS07-0021 SupraCatal) and by the China Scholarship Council (CSC, PhD grant of Y.L.). Jacques Jestin (LLB, Saclay) is acknowledged for assistance with SANS experiment. Claire Troufflard and Aurélie Bernard are acknowledged for performing VT-NMR analyses.

\section{Conflicts of interest}

There are no conflicts to declare.

\section{Notes and references}

$\ddagger$ To avoid any confusion with the catalytic loading (expressed in mol\% of substrate), the amount of TPPCl is expressed in number of equivalent relatively to $\mathrm{BTA}^{\mathrm{PPh} 2}$.

$\S \mathrm{TPPNTf}_{2}$ and $\mathrm{NaCl}$, the salts generated upon the metathesis reaction, are poor hydrogen competitors and poorly soluble, respectively (Table S1)

1. (a) N. Kumagai and M. Shibasaki, Catal. Sci. Technol., 2013, 3, 41; (b) V. Blanco, D. A. Leigh and V. Marcos, Chem. Soc. Rev., 2015, 44, 5341; (c) M. Vlatković, B. S. L. Collins and B. L. Feringa, Chem. Eur. J., 2016, 22, 17080; (d) J. Choudhury, Tetrahedron Lett., 2018, 59, 487.

2. (a) F. A. Leibfarth, K. M. Mattson, B. P. Fors, H. A. Collins and C. J. Hawker, Angew. Chem. Int. Ed., 2013, 52, 199; (b) A. J. Teator, D. N. Lastovickova and C. W. Bielawski, Chem. Rev., 2016 116, 1969; (c) M. Chen, M. J. Zhong and J. A. Johnson, Chem. Rev., 2016, 116, 10167.

3. (a) K. Eichstaedt, J. Jaramillo-Garcia, D. A. Leigh, V. Marcos, S. Pisano and T. A. Singleton, J. Am. Chem. Soc., 2017, 139, 9376; (b) S. Semwal and J. Choudhury, Angew. Chem. Int. Ed., 2017, 56, 556.

4. G. Romanazzi, L. Degennaro, P. Mastrorilli and R. Luisi, ACS Catal., 2017, 7, 4100.

5. (a) J. B. Wang and B. L. Feringa, Science, 2011, 331, 1429; (b) M. Vlatković, L. Bernardi, E. Otten and B. L. Feringa, Chem. Commun., 2014, 50, 7773; (c) D. P. Zhao, T. M. Neubauer and B. L. Feringa, Nat. Commun., 2015, 6, 6652; (d) M. Vlatković, J. Volaric, B. S. L. Collins, L. Bernardi and B. L. Feringa, Org. Biomol. Chem., 2017, 15, 8285; (e) C. T. Chen, C. C. Tsai, P. K. Tsou, G. T. Huang and C. H. Yu, Chem. Sci., 2017, 8, 524.
6. G. Storch and O. Trapp, Angew. Chem. Int. Ed., 2015, 54, 3580.

7. (a) S. Mortezaei, N. R. Catarineu and J. W. Canary, J. Am. Chem. Soc., 2012, 134, 8054; (b) S. Mortezaei, N. R. Catarineu, X. Y. Duan, C. H. Hu and J. W. Canary, Chem. Sci., 2015, 6, 5904; (c) S. Mortezaei, N. R. Catarineu and J. W. Canary, Tetrahedron Lett., 2016, 57, 459.

8. B. A. F. Le Bailly, L. Byrne and J. Clayden, Angew. Chem. Int. Ed., 2016, 55, 2132.

9. (a) T. Yamamoto, T. Yamada, Y. Nagata and M. Suginome, J. Am. Chem. Soc., 2010, 132, 7899; (b) Y. Nagata, T. Nishikawa and M. Suginome, J. Am. Chem. Soc., 2014, 136, 15901; (c) Y. Nagata, T. Kuroda, K. Takagi and M. Suginome, Chem. Sci., 2014, 5, 4953; (d) Y. Akai, L. Konnert, T. Yamamoto and M. Suginome, Chem. Commun., 2015, 51, 7211; (e) Y. Nagata, R. Takeda and M. Suginome, Chem. Commun., 2015, 51, 11182; (f) Y.-Z. Ke, Y. Nagata, T. Yamada and M. Suginome, Angew. Chem. Int. Ed., 2015, 54, 9333; (g) Y. Nagata, T. Nishikawa and M. Suginome, ACS Macro Lett., 2016, 5, 519; (h) Y. Yoshinaga, T. Yamamoto and M. Suginome, ACS Macro Lett., 2017, 6, 705; (i) J. M. Zimbron, X. Caumes, Y. Li, C. M. Thomas, M. Raynal and L. Bouteiller, Angew. Chem. Int. Ed., 2017, 56, 14016; (j) Y. Nagata, T. Nishikawa, M. Suginome, S. Sato, M. Sugiyama, L. Porcar, A. Martel, R. Inoue and N. Sato, J. Am. Chem. Soc., 2018, 140, 2722. 10. (a) M. Vaquero, L. Rovira and A. Vidal-Ferran, Chem. Commun., 2016, 52, 11038; (b) X. C. Zhang, Y. H. Hu, C. F. Chen, Q. Fang, L. Y. Yang, Y. B. Lu, L. J. Xie, J. Wu, S. J. Li and W. J. Fang, Chem. Sci., 2016, 7, 4594.

11. Z. S. Kean, S. Akbulatov, Y. C. Tian, R. A. Widenhoefer, R. Boulatov and S. L. Craig, Angew. Chem. Int. Ed., 2014, 53, 14508.

12. Q. Y. Zhang, X. L. Cui, L. Zhang, S. Z. Luo, H. Wang and Y. J. Wu, Angew. Chem. Int. Ed., 2015, 54, 5210.

13. L. Hong, W. S. Sun, D. X. Yang, G. F. Li and R. Wang, Chem. Rev., 2016, 116, 4006.

14. G. Storch and O. Trapp, Nature Chem., 2017, 9, 179.

15. G. W. Coates and R. M. Waymouth, Science, 1995, 267, 217.

16. (a) M. H. Liu, L. Zhang and T. Y. Wang, Chem. Rev., 2015, 115, 7304; (b) E. Yashima, N. Ousaka, D. Taura, K. Shimomura, T. Ikai and K. Maeda, Chem. Rev., 2016, 116, 13752.

17. J. Jiang, G. H. Ouyang, L. Zhang and M. H. Liu, Chem. Eur. J., 2017, 23, 9439.

18. (a) M. Raynal, F. Portier, P. W. N. M. van Leeuwen and L. Bouteiller, J. Am. Chem. Soc., 2013, 135, 17687; (b) A. Desmarchelier, X. Caumes, M. Raynal, A. Vidal-Ferran, P. W. N. M. van Leeuwen and L. Bouteiller, J. Am. Chem. Soc., 2016, 138, 4908.

19. P. Besenius, J. Polym. Sci. Pol. Chem., 2017, 55, 34.

20. T. Pinault, C. Cannizzo, B. Andrioletti, G. Ducouret, F. Lequeux and L. Bouteiller, Langmuir, 2009, 25, 8404.

21. Reversible binding of chloride anions to metal centres or thiourea functions has been exploited to control the activity but not the selectivity of switchable catalysts, see: (a) H. J. Yoon, J. Kuwabara, J. H. Kim and C. A. Mirkin, Science, 2010, 330, 66; (b) G. Foli, C. S. D'Elia, M. Fochi and L. Bernardi, RSC Adv., 2016, 6, 66490; (c) M. R. Kita and A. J. M. Miller, Angew. Chem. Int. Ed., 2017, 56, 5498.

22. (a) Q. Shen, T. Ogata and J. F. Hartwig, J. Am. Chem. Soc., 2008, 130, 6586; (b) B. P. Fors, N. R. Davis and S. L. Buchwald, J. Am. Chem. Soc., 2009, 131, 5766.

23. S. Allenmark, Chirality, 2003, 15, 409.

24. N. Mezailles, L. Ricard and F. Gagosz, Org. Lett., 2005, 7, 4133.

25. (a) A. Desmarchelier, M. Raynal, P. Brocorens, N. Vanthuyne and L. Bouteiller, Chem. Commun., 2015, 51, 7397; (b) A. Desmarchelier et al. Soft Matter, 2016, 12, 7824; (c) X. Caumes, A. Baldi, G. Gontard, P. Brocorens, R. Lazzaroni, N. Vanthuyne, C. Troufflard, M. Raynal and L. Bouteiller, Chem. Commun., 2016, 52,13369 . 